\title{
Knowledge about goitre among female school-going children in Wellega Province, Ethiopia
}

\author{
ZEKARIAS F. ABESSA ${ }^{1}$ and YOHANA J. MASHALLA ${ }^{1,2^{*}}$ \\ 'Department of Health Studies, University of South Africa, Johannesburg, Republic of South Africa \\ ${ }^{2}$ Faculty of Health Sciences, University of Botswana, Gaborone, Botswana
}

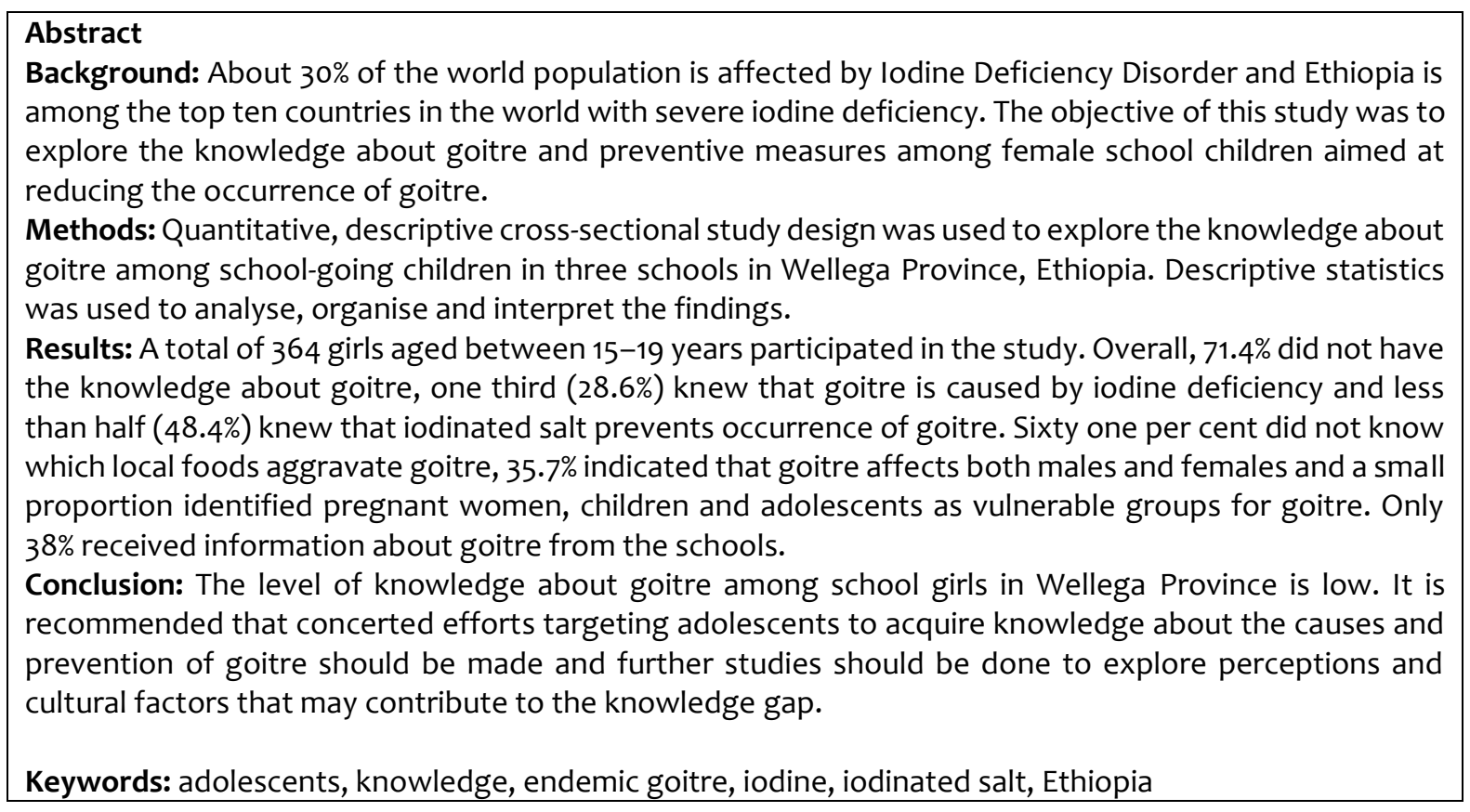

\section{Introduction}

Thyroid is an important endocrine gland necessary for maintenance of homeostasis in the body by synthesising thyroid hormones (thyroxine and triiodothyronine). In the synthesis of thyroid hormones, iodine is required as an essential ingredient. lodine exists in foodstuffs (milk, meat and sea foods) as inorganic iodides which are efficiently absorbed in the gastrointestinal tract (Yen, 2001; Kumar \& Clark 2006). Mountainous areas in the world including the Himalayas and east and west Wellega Provinces in Ethiopia are among places deficient in iodine in the soil resulting in iodine deficiency disorder (IDD) (FMH, 2004; Ney-Bruin et al., 2007). A deficiency of iodine intake leads to insufficient/inadequate production of thyroid hormones and enlargement of the thyroid gland. Iodine Deficiency Disorder or endemic goitre is a global problem occurring in many remote

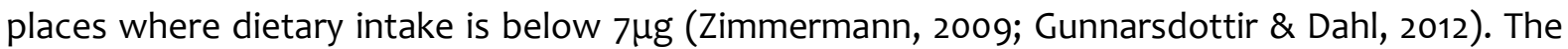
most serious consequence of IDD is increased mortality and mental retardation in infants (FAO/WHO, 2005; Brownstein, 2006; WHO, 2007).

Global estimates indicate that about $30 \%$ of the world population is affected by IDD (WHO/UNICEF/ICCIDD, 2008). In 2005, the world Health Organisation reported that the total global goitre prevalence was 28.3\% (Andersson et al., 2005). Endemic goitre affects millions of people in low-income countries mainly due to deficiency of iodine in food sources and factors that affect the bioavailability of iodine sources (Abuye et al., 2008; Ashraf et al., 2010). Ethiopia is the second on the list of the top 10 iodine-deficient countries in the world (Andersson et al., 2012). The findings of a national-wide study in Ethiopia indicate that the national total global goitre prevalence among school children was 39.9\% (Abuye et al., 2007).

\footnotetext{
* Correspondence Email: yohana.mashalla@mopipi.ub.bw
} 
Enlarged thyroid gland (goitre) occurs in adolescents at puberty and girls are more affected than boys (Tigabu et al., 2017). Protein energy malnutrition, selenium deficiency and goitrogenic factors in food sources like cassava, millet, soya bean, bamboo shoots, turnip and Kale (borecole) aggravate iodine deficiency (Abuye et al., 2008). Studies have indicated that iodinated salt is effective in reducing the impact of IDD (WHO/UNICEF/ICCIDD, 2008; Zhao et al., 2014). Therefore, Ethiopia like many other developing countries has adopted the universal salt iodination targeting to reach $90 \%$ of the population (Global Alliance, 2018). Contrary to that expectation, a recent report in Ethiopia shows that while about $88 \%$ of the salt in the country is iodised, only $23.2 \%$ of the population have access to adequately iodinated salt (EPHI, 2014). The report raises a question why iodinated salt uptake is still low when a significant percentage of salt in the country is iodinated.

The few studies which explored the knowledge, awareness and perception of endemic goitre among women aged 15-49 years in Ethiopia have indicated that communities' perception of goitre varied from area to area. With the exception of Addis Ababa and Tigray regions where relatively a good proportion of women had some knowledge about IDD, about $90 \%$ of the respondents in all other regions didn't know the importance of iodised salt, the causes of goitre and had no concern of goitre because it is not a painful condition (Ney-Bruin et al., 2007; Abuye et al., 2007). Establishing the level of knowledge, awareness and perceptions about goitre and associated factors in such communities is therefore important. This study aimed to explore the knowledge about goitre among female school-going children in Wellega Province, Ethiopia. Such information will be useful to inform key strategic stakeholders in planning, designing and implementing strategies to reduce the impact of goitre among female school-age adolescents

\section{Materials and Methods}

\section{Study area and design}

This study was carried out in Wellega Province, Ethiopia. Urban high schools in Kelem, Nekemte and Derge were selected. Non-experimental, descriptive, cross-sectional study design was used to explore the knowledge and perceptions about endemic goitre as well as the factors influencing its occurrence among female school-aged adolescents. The study population included high school female adolescents aged 14-19 years old. Male children of all ages were excluded from the study because of low occurrence of goitre among male children (Hailu et al., 2016). Females less than 14 years and all those above 19 years were also excluded from the study.

\section{Sampling and data collection}

The sample size was determined from a total of 3,750 sample frame from the students' roster from each high school. Using a simple random sampling, the names of eligible participants were selected randomly from the sample frame. Numbers were assigned to each name in the sampling frame then selected randomly to obtain the sample. Based on the sample frame of 3,750 of which 1,551 (41.4\%), 1,140 (30.4\%) and 1,059 (28.2\%) participants were drawn from Kelem, Nekemte and Derge High Schools, respectively. Using statistical significance of 0.05; standard normal distribution for 95\% Confidence Interval 1.96; goitre prevalence 37\% (Ney-Bruin et al., 2007) and 10\% design effect the calculated sample was 364 distributed according to the proportion contribution of each school. Data were collected using a semi-structured questionnaire by asking questions during face to face interview.

\section{Data analysis}

Epi-Info (version 3.2.2) was used to analyse the data. Descriptive statistics and frequency were used to organise, describe and synthesise data in order to discover and describe the variables including knowledge about goitre, sources of information about the disease, sources of dietary iodine and 
preventive measures as factors influencing attitude and practices towards goitre in the study population.

\section{Ethical considerations}

The study was carried out in line with the principles of ethics for research involving human subjects. The research proposal received ethical clearance from the University of South Africa (UNISA), Department of Health Studies, Higher Degrees Committee. Permission to carry out the study was granted by the Oromia Regional State Education Office, Nekemte, Ethiopia.

\section{Results}

Table 1 shows the age distribution of the respondents, the frequency and percentages of the knowledge about goitre. Most respondents (85.4\%) were below 18 years of age, of which about $50 \%$ were in the age range between 15 and 16 years. The older children ( $18-19$ years) accounted for $14.6 \%$ of the respondents.

Table 1: Demographic characteristics, knowledge about goitre and sources of dietary iodine among female school children ( $\mathrm{N}=364)$

\begin{tabular}{|c|c|c|c|}
\hline Variables & Response & Frequency & Percentage \\
\hline \multirow[t]{6}{*}{ Age (years } & 14 & 61 & 16.8 \\
\hline & 15 & 91 & 25.0 \\
\hline & 16 & 93 & 25.5 \\
\hline & 17 & 66 & 18.1 \\
\hline & 18 & 32 & 8.8 \\
\hline & 19 & 21 & 5.8 \\
\hline \multirow[t]{8}{*}{ Knowledge on goitre } & Caused by iodine deficiency & 104 & 28.6 \\
\hline & Disease of the neck & 98 & 26.9 \\
\hline & I don't know & 139 & 38.2 \\
\hline & $\begin{array}{l}\text { Caused by drinking } \\
\text { contaminated water }\end{array}$ & 9 & 2.5 \\
\hline & Caused by lack of vitamin $C$ & 4 & 1.1 \\
\hline & Hereditary disease & 2 & 0.5 \\
\hline & Vitamin A deficiency & 4 & 1.1 \\
\hline & Lack of salt & 4 & 1.1 \\
\hline \multirow{8}{*}{$\begin{array}{l}\text { Knowledge on the sources of } \\
\text { dietary iodine }\end{array}$} & Meat and iodized salt & 2 & 0.5 \\
\hline & lodized salt & 98 & 26.9 \\
\hline & I don't know & 175 & 48.1 \\
\hline & From balanced diet & 19 & 5.2 \\
\hline & Fruit and Vegetables & 18 & 4.9 \\
\hline & Kidney and liver & 1 & 0.3 \\
\hline & Every salt & 45 & 12.4 \\
\hline & From fat & 6 & 1.6 \\
\hline
\end{tabular}

About one third (28.6\%) of the respondents had the knowledge that goitre is caused by iodine deficiency as compared to $38.2 \%$ who did not. About a quarter (26.9\%) of the school girls responded that goitre is a disease of the neck while $2.5 \%$ believed that goitre is caused by drinking contaminated water. Overall, about $71.4 \%$ of the respondents did not have correct knowledge on the causes of goitre. Similarly, $48.1 \%$ of the children had no knowledge of the common food sources 
of iodine and $27 \%$ believed that iodized salt is the only source of iodine. Another $12.4 \%$ believed that iodine can be obtained from all forms of dietary salt and the remaining $12.6 \%$ responded that a balanced diet, fruits, vegetables, fat, meat, kidney and liver are good sources of dietary iodine.

\section{Sources of information about goitre}

About half of the girls (48\%) did not respond to the question. Of those who responded, only $38 \%$ got the information from schools and another $14 \%$ received information from other sources including health facilities (5\%), radio (4\%), people (4\%) and newspapers (1\%) (Figure 1).

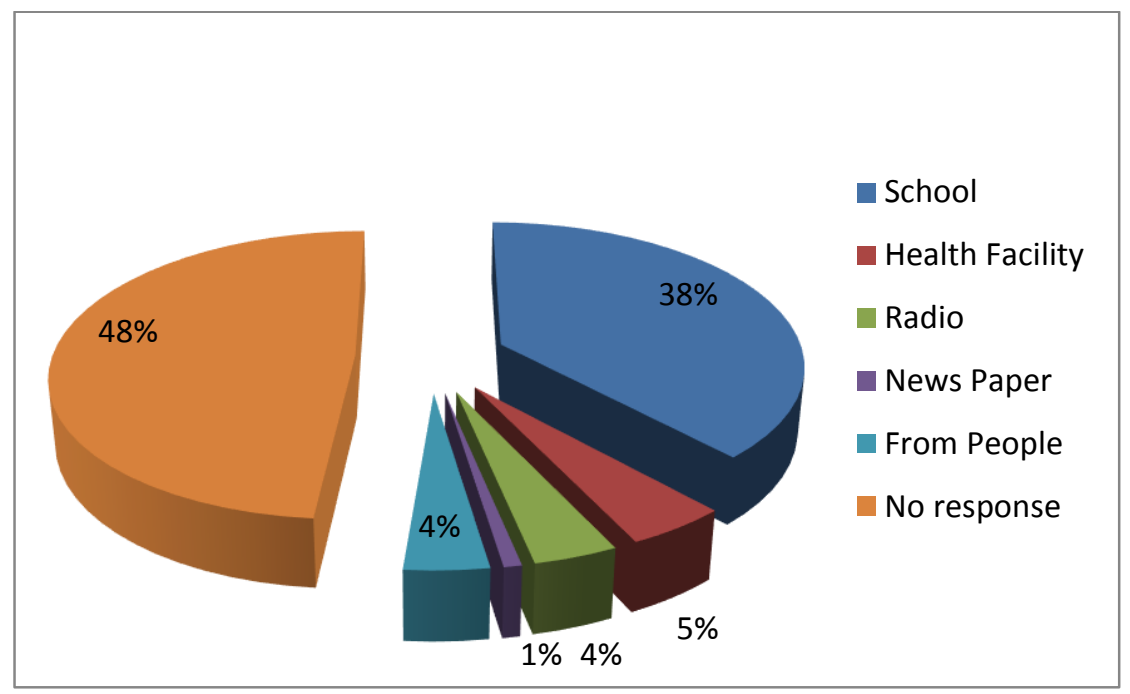

Figure 1: The sources of information about goitre among school children

\section{Knowledge on prevention of goitre development}

The responses to the question on the knowledge about which foods when eaten in adequate quantities would prevent occurrence of goitre are presented in Figure 2. Only $48.4 \%$ knew that eating iodised salt would prevent occurrence of goitre and $40.1 \%$ did not know.

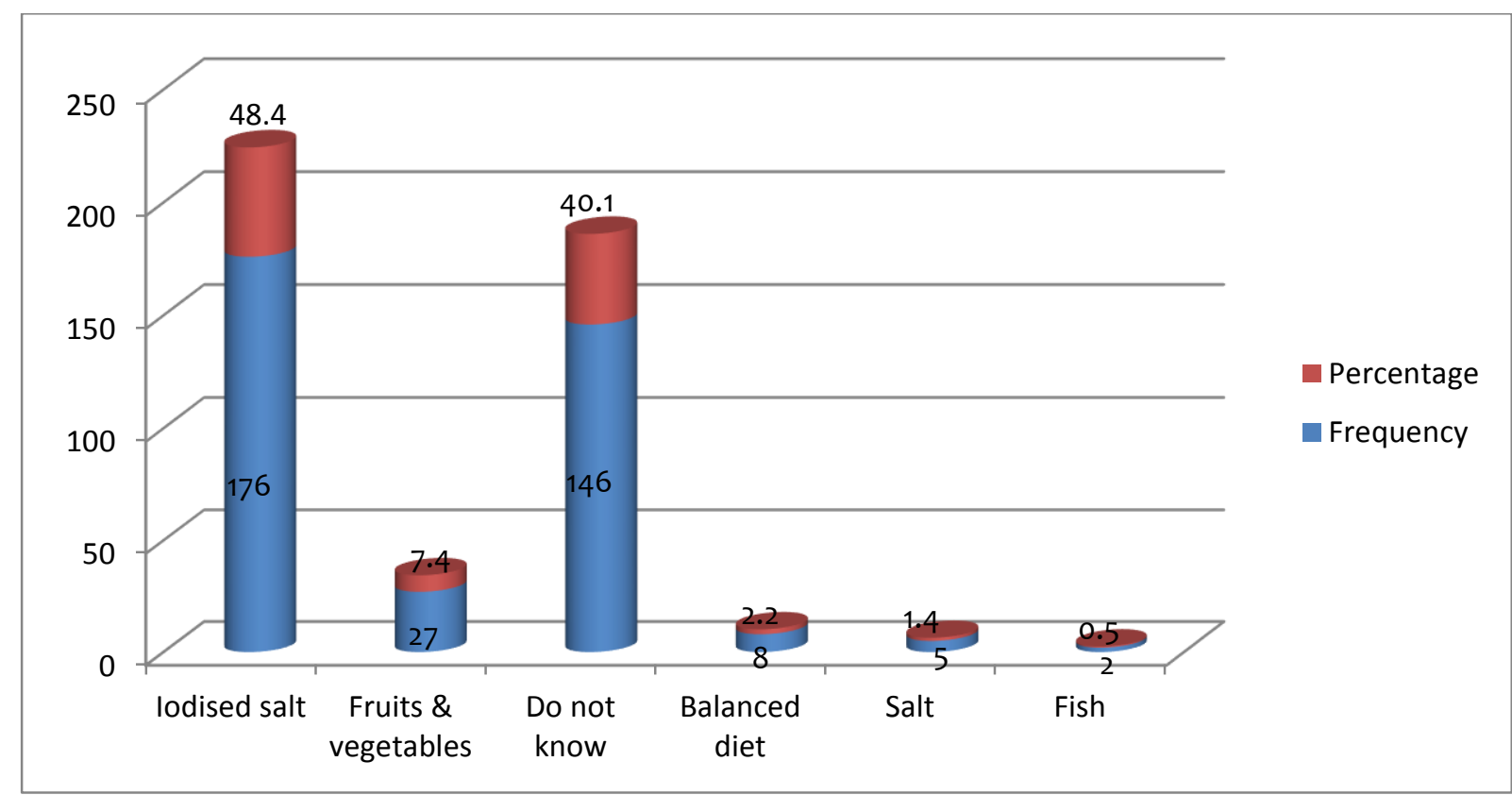

Figure 2: The level of knowledge among female school children on the types of foods when eaten in adequate quantities would prevent occurrence of goitre 
Figure 3 shows that $66 \%$ of the children knew that iodised salt is a source of iodine and another $11 \%$ responded that foods (without specifying the types) are sources of iodine. Water and all forms of salt are sources of iodine were indicated by $5.0 \%$ and 3\%, respectively.

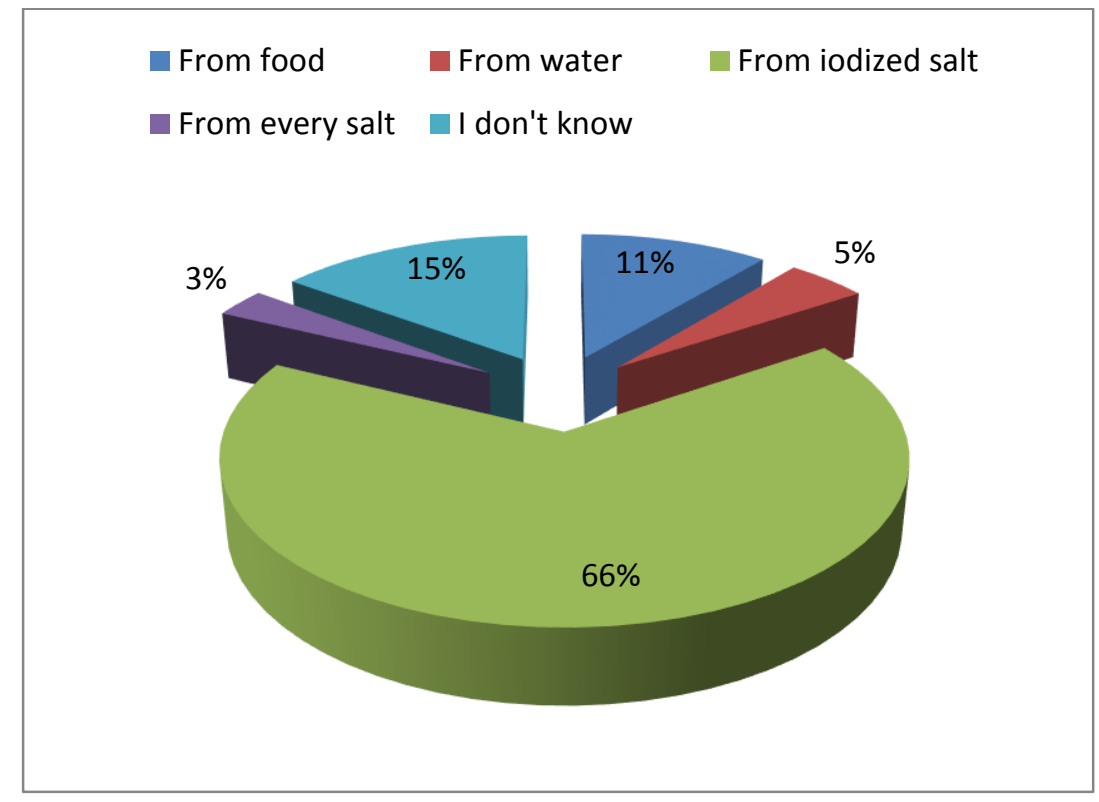

Fig 3: The knowledge about the sources of iodine among female school children

\section{Knowledge about vulnerable groups in the community}

Knowledge that pregnant women, children and adolescents are the major vulnerable groups was observed in $9.1 \%$. About a quarter (24.5\%) of the school girls did not have the knowledge of which population groups are vulnerable to goitre (Figure 4). About $35.7 \%$ indicated that goitre affects both male and female equally and another $16.8 \%$ indicated that it affects females only.

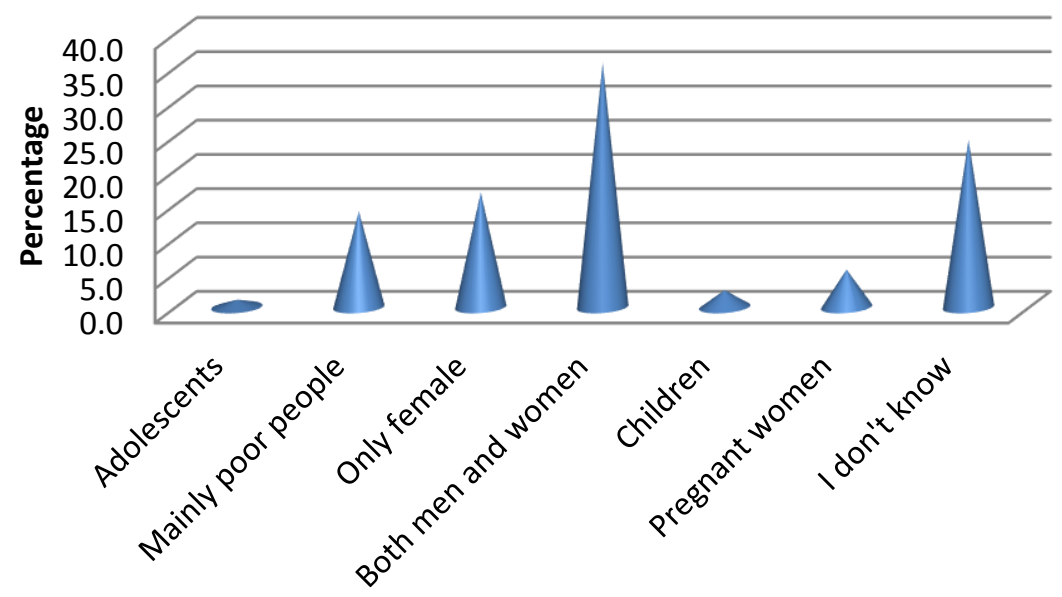

Figure 4: The knowledge of the respondents about the vulnerable groups commonly affected by goitre

\section{Discussion}

Goitre, locally known in the study area as "Kufa Morma" is a global public health problem that has been extensively studied both in adults and young people. Knowledge is critical in understanding concepts, in designing and taking appropriate actions to resolve issues. This study shows a significant proportion of the adolescent girls did not have correct knowledge of goitre and only 
one third had the knowledge that goitre is caused by inadequate dietary intake of iodine. Our findings are relatively lower than reported in a study in India where no one had correct knowledge of the causes of goitre and $44 \%$ felt that goitre affects females only (Mallik et al., 1998). Similar low knowledge of goitre was reported in South Africa where $86.9 \%$ of the respondents had no knowledge of what iodine is and even those who claimed to know, about $5 \%$ said it was a vitamin (Sebotsa et al., 2009). The study in South Africa also indicated that about three quarters of the respondents had no knowledge of iodine sources and only a few knew that iodised salt is a source of iodine. In this study, about half of the children had no knowledge of the common food sources of iodine (milk, meat, sea foods) as compared to over three quarters reported in South Africa (Sebotsa et al., 2009).

The knowledge about foods that may aggravate goitre is required for empowering communities to take preventive measures at the households in reducing the occurrence of goitre. In this study, most children did not have the correct knowledge of the foods (e.g. cassava) that when eaten may aggravate goitre development (Osman et al., 1993; Abuye et al., 2008). Such foods should either be avoided or be carefully processed in order to reduce their effects on iodine absorption. An interesting finding was that avoiding drinking water dripping on the leaves of a local plant "Enset" and not eating its flowers would reduce the occurrence of goitre. This finding is supported by a previous report in the area suggesting that goitre has cultural roots within the community which require further exploration (Ney-Bruin et al., 2007).

Studies have indicated higher prevalence of goitre among females possibly because of their early onset of adolescent growth spurt than their male counterparts (Kamath et al., 2009; Hailu et al., 2016). While a study in India (Kamath et al., 2009) has reported that respondents believed that goitre affects females only our findings indicate that the school girls understand better that although the disease is seen more among females, males may also be affected. However, one quarter of the children did not know which population groups are most vulnerable to goitre. Only a small percentage (9.1\%) knew that pregnant women, children and adolescents constitute important vulnerable groups (Mallik et al., 1998). Similarly, while about two third of the children responded that goitre can be prevented by eating iodine containing foods, about $14 \%$ of them did not know how goitre can be prevented. In addition, more than two thirds of the school girls did not know how iodine prevents enlargement of thyroid gland.

This study supports the previous report (EPHI, 2014) that a small population in Ethiopia has access to iodised salt possibly because of low level of knowledge about the disease and how it can be prevented. We focused on adolescents because they are the future generation and imparting knowledge among this population segment is necessary to empower communities to receive and process information appropriately for their wellbeing. Understanding the level of knowledge and sources of the information about goitre is required in order to identify information and knowledge gaps necessary for designing appropriate preventive measures. Our study shows that about half of the girls did not respond to the question on their sources of information about goitre suggesting that they may not have had access to information about goitre. Among those who had information sources a third received the information from school and very small percentages received information from health facilities, radio and printed media. Schools play a key role in providing accurate and reliable information and creating enabling environment as well as supportive services that assist adolescents to make informed decisions regarding social issues that will ensure them a better future. Our findings raise fundamental questions on where and when is goitre information availed to young people in these endemic areas? It is recommended that concerted effort is needed to empower communities to acquire accurate knowledge about the causes and goitre prevention. Schools in endemic areas should review academic curricula in and mainstream goitre content in their programmes. In addition, further studies are needed to explore cultural factors that contribute to perceptions and attitude towards goitre and the country's' iodised salt supply-chain should be audited in order to explore why iodised salt uptake by the population is still low. 
The major limitations of this study include the fact that the study focused only on female school adolescents in the study sites and excluded those out of school adolescents who may be facing a similar situation. The knowledge gap therefore could be an underestimation of the extent of the problem therefore, may not be representative of the total regional population or the country.

\section{Acknowledgements}

We would like to express our sincere gratitude and thanks to all those who participated in the study.

\section{Author contributions}

AZF conceived, designed the study, collected and analysed as well as interpreted the results. YM supervised data collection and analysis. All authors wrote and proof read the manuscript.

\section{Conflict of interest}

The authors declare no conflict of interest to this study.

\section{References}

Abuye, C., Berhane, Y., Akalu, G., Getahun, Z. \& Ersumo, T. (2007) Prevalence of goitre in children 6 to 12 years of age in Ethiopia. Food Nutrition Bulletin 28:391-398.

Abuye, C., Berhane, Y. \& Ersumo, T. (2008) The role of changing diet and attitude on goitre prevalence in five regional state of Ethiopia. East African Journal of Public Health 5: 163-168.

Andersson, M., Kurumbunathan, V. \& Zimmermann, MB. (2012) Global iodine status in 2011 and trends over the past decade. Journal of Nutrition 142: $744-750$.

Andersson, M., Takkouche, B., Egli, I., Allen, H.E., de Benoist, B. (2005) Current global iodine status and progress over the last decade towards the elimination of iodine deficiency. Bulletin of the World Health Organisation 83: $518-525$.

Ashraf, A., Amini, M. \& Hovsepain S. (2010) Prevalence of Goitre in Isfahan, Iran, Fifteen years after initiation of Universal Salt lodization. Journal of Health, Population and Nutrition 28(4): 351358.

Brownstein, D. (2006) lodine: Why You Need It, Why You Can't Live Without It. 2nd Edition. Medical Alternatives Press: Michigan.

EPHI (2014) National salt iodisation coverage towards prevention of iodine deficiency disorder in Ethiopia. Ethiopia Public Health Institute. Available from: https://www.ephi.gov.et/images/pictures/USI\%20persentation_Forum_October_25_2014.pd f.

FAO/WHO (2005) Vitamin and mineral requirements in human nutrition, $2^{\text {nd }}$ Edition. World Health Organisation, Geneva. Available from: http://whqlibdoc.who.int/publications/2004/9241546123.pdf.

FMH (2004) Guidelines for Control and Prevention of Micronutrient Deficiencies. Federal Ministry of Health 13 - 26. Addis Ababa, Ethiopia

Global Alliance (2018 Global Alliance for Improved Nutrition. Ethiopia Universal Salt Iodisation. Available from https://www.gain-health.org/knowledge-centre/project/ethiopia-universalsalt-iodisation. Cited May 2018.

Gunnarsdottir, I. \& Dahl, L. (2012) lodine intake in human nutrition: a systematic literature review. Food Nutrition Research 56: 19731. 
Hailu, S., Wubshet, M., Woldie, H. \& Tariku A. (2016) lodine deficiency and associated factors among school children: a cross-sectional study in Ethiopia. Archives of Public Health 74: 46.

Kamath, R., Bhat, V., Rao, S., Acharya, D., Kapil, U., Kotian, M.S. \& Nayak, D.S. (2009) Prevalence of goitre among school children in Belgaum district India. Journal of Paeditrics 76: 825 - 828.

Kumar, P. \& Clark, M. (2005) Clinical Medicine. Elsevier Saunders, $6^{\text {th }}$ ed. 2005; 249.

Mallik, A.K., Anand, K., Pandav, C.S., Achar, D.P., Lobo, J., Karmarkar, M.G. \& Nath, L.M. (1998) Knowledge beliefs and practices regarding iodine deficiency disorders among the tribal in Car Nicobar. Indian Journal of Paediatrics 65: 115 - 120.

Ney-Bruin, C., Mommers, F., Roelofsen, G. \& Mommers E. (2007) Intervention of Goitre prevalence and Awareness on iodine deficiency disorder in West Ethiopia. Foundation Strumeth: The Netherlands.

Osman, B.A., Ng, M.L., Bakar, A.A. \& Khalid, B.A. (1993) The effect of cassava leave intake on thyroid hormone and urinary iodine. East African Medical Journal 70: 314-315.

Sebotsa, M.L.D., Dannhauser, A., Mollentze, W.F., Oosthuizen, G.M., Mahomed, F.A. \& Jooste, P.L. (2009) Knowledge, attitude and practices regarding iodine among patients with hyperthyroidism. African Journal of Clinical Nutrition 22: 19-21.

Tigabu, E., Bekele, K.B. \& Dachew, B.A. (2017) Prevalence of goitre and associated factors among school children in northeast Ethiopia. Epidemiology \& Health 39:e2017055.

WHO (World Health Organization) lodine deficiency in Europe. (2007) A continuing public health problem; Geneva.

WHO/UNICEF/ICCIDD. (2008). Assessment of the iodine deficiency disorders and monitoring their elimination. A Guide for program managers; Geneva.

Yen, P.M. (2001) Physiological and molecular basis for thyroid hormone action. Physiology Review 81: 1097-1142.

Zhao, W., Han, C., Shi, X., Xiong, C., Sun, J., Shan, Z. \& Teng, W. (2014) Prevalence of goitre and thyroid nodules before and after implementation of the universal salt iodisation programme in mainland China from 1985 to 2014: a systematic review and meta-analysis. PLOS ONE 9:e109549.

Zimmermann, M.B. (2009) lodine deficiency. Endocrine Review 3094: 378-408. 